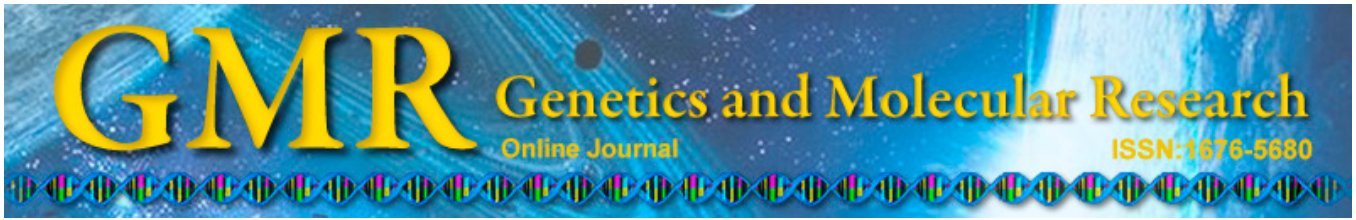

\title{
Association of cytokine gene polymorphisms with susceptibility to invasive candidiasis
}

\author{
R.T. Sun ${ }^{1 *}$, W.J. Tian ${ }^{2 *}$, X.W. Xing ${ }^{2}$, S.H. Gao ${ }^{2}$ and S.B. Wang ${ }^{2}$ \\ ${ }^{1}$ Clinical Laboratory, Weihai Municipal Hospital, Weihai, China \\ ${ }^{2}$ Clinical Laboratory, Shandong Provincial Hospital Affiliated to Shandong \\ University, Shandong, China \\ *These authors contributed equally to this study. \\ Corresponding author: R.T. Sun \\ E-mail: sunrongtong556@163.com
}

Genet. Mol. Res. 14 (2): 6859-6864 (2015)

Received January 26, 2015

Accepted February 27, 2015

Published June 18, 2015

DOI http://dx.doi.org/10.4238/2015.June.18.29

\begin{abstract}
The aim of this study was to investigate the role of cytokine genes in the susceptibility to Candida infection. A total of 275 consecutive patients diagnosed with Candida infection were selected between May 2010 and May 2011, along with 305 uninfected controls. Genotyping of the IL-1 $\beta$ gene polymorphisms (IL1 $\beta$ ) rs1143634, IL1 $\beta$ rs16944, IL8 rs4073, IL10 rs1800872, and IL10 rs1800896 was carried out using a 384-well plate format on the Sequenom MassARRAY platform. Patients with invasive Candida infections were more likely to have had an immunocompromised state, hematopoietic stem cell transplantation, solid organ transplant, solid tumor, chemotherapy within the past three months, neutropenia, surgery within the past 30 days, acute renal failure, liver failure, and/or median baseline serum creatinine. Conditional logistic regression analyses found that individuals with the rs1800896 GG genotype were associated with a higher risk of invasive Candida infections than those carrying the AA genotype (odds ratio $=0.61,95 \%$ confidence interval $=0.37-0.94$ ). From the results of this case-control study, we suggest that the cytokine
\end{abstract}


IL-10 gene rs1800896 polymorphism might play a role in the etiology of invasive Candida infections.

Key words: Cytokine gene; IL-1 $\beta$; IL-8; IL-10; Polymorphism; Invasive Candida infection

\section{INTRODUCTION}

Invasive candidiasis is a pervasive nosocomial infection. Patients with invasive candidiasis might have complications such as endocarditis, abscesses, or chronic-disseminated candidiasis. Previous studies have reported that persistent fungemia is one of the complications found in patients with candidemia, occurring in over 10\% of the patients (Da Matta et al., 2010). Some studies have shown that the immune response can influence the infection, comorbidities, and efficacy of pharmacologic therapy of patients with invasive candidiasis (Garey et al., 2006).

A previous study has further found that both the innate and adaptive immune mechanisms play an important role in the host defense against Candida species (Romani, 2004), and that the immune system can defend against fungal pathogens through the phagocytosis and killing of invading pathogens and through the activation of adaptive immunity by antigen presentation and secretion of proinflammatory cytokines (Netea et al., 2008). It has been reported that adaptive fungal immunity stimulates host responses to pathogens through protective cellular T-helper 1 (Th1) cytokines such as interferon-c (IFNc), as well as through humoral Th2 responses that might exert maladaptive anti-inflammatory effects by the release of interleukin (IL)-4 and IL-10. One study found that polymorphisms in $I L 10$ and $I L 12 \beta$ that result in low production of proinflammatory cytokines were associated with persistent fungemia in patients with candidemia (Johnson et al., 2012). However, few studies have investigated the role of cytokine gene variants in the susceptibility to Candida infection. Therefore, we aimed to investigate the role of cytokine genes in the susceptibility to Candida infection in patients with candidemia.

\section{MATERIAL AND METHODS}

\section{Patients, treatments, and clinical variables}

A total of 275 consecutive patients diagnosed with Candida infection were selected from the Weihai Municipal Hospital between May 2010 and May 2011. All patients were identified by more than one positive blood cultures for Candida species in the clinical microbiology laboratory. Blood samples were obtained from all patients. The controls consisted of 305 subjects who were randomly selected from individuals who came to the Health Check Center; they were not infected with invasive candidiasis and did not carry any other invasive fungal infection. Written informed consent was provided by all subjects. Our study was approved by the Ethics Committee of the Weihai Municipal Hospital.

The basic clinical and microbiological variables were selected from medical records, and assessed for their relationship with the clinical outcome of the patients. The clinical data included gender, age, and immunocompromised host status. When patients 
showed the presence of Candida species at normally sterile sites outside the bloodstream (excluding the urine), the disease was regarded as disseminated, and then further defined as acute or chronic. Persistent fungemia was defined as $\geq 5$ days of persistently positive blood cultures for the same Candida species. All infected patients were followed for three months to assess their clinical outcome.

\section{Genotyping}

All patients were asked to provide $5 \mathrm{~mL}$ venous blood, and their genomic DNA was isolated using a Qiagen Blood Kit (Qiagen, Chastworth, CA, USA) according to manufacturer instructions. Genotyping of the IL-1 $\beta$ gene (IL1 $\beta$ ) rs 1143634, IL1 $\beta$ rs16944, IL8 rs4073, IL10 rs1800872, and IL10 rs1800896 polymorphisms was carried out using a 384-well plate format on the Sequenom MassARRAY platform (Sequenom, San Diego, CA, USA). The Sequenom Assay Design 3.1 software (Sequenom) was conducted to design primers for polymerase chain reaction amplification and single base extension assays. For the rs 1143634 , the forward and reverse primers were 5'-TGCTCCACATTTCAGAACCTATCTTCGTC-3' and 5'-CTTGTTGC TCCATATCCTGTCCCTGGAGG-3', respectively. For rs16944, the forward and reverse primers were 3'-CAGAGGCTCCTGCAATTGACA-5' and 3'-GGTCTCTACCTTGGGTGCTGT TC-5', respectively. For rs4073, the forward and reverse primers were 5'-CTAGAAATAAA AAAGCATACAT-3' and 5'-CTAGAAATAAAAAAGCATACAA-3', respectively. For rs 1800872 , the forward and reverse primers were 5'-GGTAAAGGAGCCTGGAACACA TC-3' and 5'-GCCCTTCCATTTTACTTTCCAGAGA-3', respectively. For rs1800896, the forward and reverse primers were 5'-ACACACACAAATCCAAGACAACACT-3' and 5'-GCTGGATAGGAGGTCCCTTACTTT-3', respectively. Polymerase chain reaction (PCR) amplification was performed in a $25 \mu \mathrm{L}$ total volume containing $50 \mathrm{ng}$ genomic DNA, $0.1 \mu \mathrm{L}$ dNTPs, 1.25 U Taq DNA polymerase (Promega Corporation, Madison, WI, USA), and $21 \mu \mathrm{L}$ forward and reverse primers. The cycling program involved preliminary denaturation at $95^{\circ} \mathrm{C}$ for $2 \mathrm{~min}$, followed by $45 \mathrm{step}$ cycles of denaturation at $95^{\circ} \mathrm{C}$ for $30 \mathrm{~s}$, annealing at $56^{\circ} \mathrm{C}$ for $30 \mathrm{~s}$, extension at $72^{\circ} \mathrm{C}$ for $60 \mathrm{~s}$, and a final extension at $72^{\circ} \mathrm{C}$ for $5 \mathrm{~min}$. The PCR products were analyzed by $1.0 \%$ agarose gel electrophoresis. For quality control, $10 \%$ of the subjects were randomly selected for repeated sample genotyping, the results of which showed $100 \%$ concordance.

\section{Statistical analysis}

Continuous variables are reported as means \pm standard deviation (SD), while categorical variables are reported as frequencies and percentages (\%). The odds ratios (ORs) and corresponding $95 \%$ confidence intervals (CIs) were calculated by unconditional logistic regression analysis and utilized to assess the potential association between $I L-1 \beta$ rs $1143634, I L-1 \beta$ rs 16944, $I L-8$ rs4073, $I L-10$ rs1800872, and $I L-10$ rs1800896 polymorphisms and the risk of Candida infection. The homozygote for the most frequent allele was regarded as the reference group. SPSS statistical package, version 11.0 (SPSS Inc., Chicago, IL, USA) for Windows was used for statistical analyses. All $\mathrm{P}$ values were two-tailed, and a difference was considered to be statistically significant when $\mathrm{P}<0.05$. 


\section{RESULTS}

There were 169 men and 106 women among the patients with invasive Candida infection, and there were 171 men and 134 women among the control subjects (Table 1). The mean age of patients and controls were $51.3 \pm 15.3$ and $52.4 \pm 14.9$ years, respectively. Of the patients with invasive Candida infection, 107 (38.91\%) were infected with Candida albicans, 85 (30.91\%) with Candida glabrata, 39 (14.18\%) with Candida parapsilosis, 30 (10.91\%) with Candida tropicalis, 11 (4.00\%) with Candida krusei, and $3(1.09 \%)$ with other Candida species. Patients with invasive Candida infections were more likely to have an immunocompromised state, had hematopoietic stem cell transplantation, solid organ transplant, solid tumor, chemotherapy within the past three months, neutropenia, surgery within the past 30 days, acute renal failure, liver failure, and/or median baseline serum creatinine.

\begin{tabular}{|c|c|c|c|c|c|c|}
\hline Variable & $\begin{array}{l}\text { Infected subjects } \\
\qquad \mathrm{N}=275\end{array}$ & $\%$ & $\begin{array}{l}\text { Controls } \\
\mathrm{N}=305\end{array}$ & $\%$ & $\begin{array}{l}t \text { or } \chi^{2} \\
\text { value }\end{array}$ & $\mathrm{P}$ value \\
\hline \multicolumn{7}{|l|}{ Gender } \\
\hline Male & 169 & 61.45 & 171 & 56.07 & & \\
\hline Female & 106 & 38.55 & 134 & 43.93 & 1.73 & 0.19 \\
\hline Age, years $($ mean $\pm \mathrm{SD})$ & & $51.3 \pm 15.3$ & & $52.4 \pm 14.9$ & 0.79 & 0.22 \\
\hline Immunocompromised state & 158 & 57.45 & 37 & 12.13 & 133.11 & $<0.001$ \\
\hline Active malignancy & 78 & 28.36 & 11 & 3.61 & 68.23 & $<0.001$ \\
\hline Hematopoietic stem cell transplantation & 4 & 1.45 & 0 & 0.00 & 4.47 & 0.05 \\
\hline Solid organ transplant & 6 & 2.18 & 0 & 0.00 & 6.72 & 0.01 \\
\hline Solid tumor & 9 & 3.27 & 6 & 1.97 & 0.98 & 0.32 \\
\hline Leukemia & 2 & 0.73 & 2 & 0.66 & 0.01 & 0.92 \\
\hline Lymphoma & 6 & 2.18 & 1 & 0.33 & 4.17 & 0.04 \\
\hline Chemotherapy within past 3 months & 31 & 11.27 & 4 & 1.31 & 25.31 & $<0.001$ \\
\hline Neutropenia (ANC, 500 cells $/ \mathrm{mm}^{3}$ ) & 17 & 6.18 & 1 & 0.33 & 16.48 & $<0.001$ \\
\hline Surgery within past 30 days & 97 & 35.27 & 33 & 10.82 & 49.72 & $<0.001$ \\
\hline Acute renal failure & 78 & 28.36 & 0 & 0.00 & 99.95 & $<0.001$ \\
\hline Liver failure & 59 & 21.45 & 0 & 0.00 & 72.85 & $<0.001$ \\
\hline Median baseline serum creatinine (mg/dL) & 3 & 1.09 & 0 & 0.00 & 3.34 & 0.11 \\
\hline Median baseline WBC count $\left(\right.$ cells $\left./ \mathrm{mm}^{3}\right)$ & 26 & 9.45 & 4 & 1.31 & 19.55 & $<0.001$ \\
\hline \multicolumn{7}{|l|}{ Candida species } \\
\hline Candida albicans & 107 & 38.91 & & & & \\
\hline Candida glabrata & 85 & 30.91 & & & & \\
\hline Candida parapsilosis & 39 & 14.18 & & & & \\
\hline Candida tropicalis & 30 & 10.91 & & & & \\
\hline Candida krusei & 11 & 4.00 & & & & \\
\hline Other Candida species & 3 & 1.09 & & & & \\
\hline
\end{tabular}

$\mathrm{SD}=$ standard deviation; $\mathrm{ANC}=$ absolute neutrophil count; $\mathrm{WBC}=$ white blood cell

The genotype distributions of $I L-1 \beta$ rs1143634, $I L-1 \beta$ rs16944, $I L-8$ rs4073, $I L-10$ rs 1800872 , and $I L-10$ rs1800896 polymorphisms were in Hardy-Weinberg equilibrium in the control subjects. Conditional logistic regression analyses found that individuals with the rs 1800896 GG genotype were associated with an increased risk of invasive Candida infections compared to those with the AA genotype $(\mathrm{OR}=0.61,95 \% \mathrm{CI}=0.37-0.94)$ (Table 2). However, we did not find significant association between $I L-1 \beta$ rs1143634, $I L-1 \beta$ rs16944, $I L-8$ rs4073, or $I L-10$ rs 180087 and risk of Candida infection. 
Table 2. Association of $I L-1 \beta$ rs $1143634, I L-1 \beta$ rs 16944, $I L-8$ rs4073, $I L-10$ rs 1800872 , and $I L-10$ rs 1800896 with susceptibility to invasive Candida infections.

\begin{tabular}{|c|c|c|c|c|c|c|}
\hline Polymorphism & Infected subjects $(\mathrm{N})$ & $\%$ & Controls (N) & $\%$ & OR $(95 \% \mathrm{CI})$ & $P$ value \\
\hline \multicolumn{7}{|l|}{$I L-1 \beta$ rs 1143634} \\
\hline $\mathrm{GG}$ & 169 & 61.45 & 181 & 59.34 & 1.0 (Ref.) & - \\
\hline GA & 97 & 35.27 & 106 & 34.75 & $0.98(0.68-1.41)$ & 0.91 \\
\hline $\mathrm{AA}$ & 9 & 3.27 & 18 & 5.90 & $0.54(0.21-1.30)$ & 0.13 \\
\hline \multicolumn{7}{|l|}{$I L-1 \beta \mathrm{rs} 16944$} \\
\hline AA & 30 & 10.91 & 46 & 15.08 & 1.0 (Ref.) & - \\
\hline GA & 130 & 47.27 & 136 & 44.59 & $1.47(0.85-2.56)$ & 0.15 \\
\hline GG & 115 & 41.82 & 123 & 40.33 & $1.43(0.82-2.52)$ & 0.18 \\
\hline \multicolumn{7}{|l|}{$I L-8$ rs 4073} \\
\hline $\mathrm{AA}$ & 57 & 20.73 & 56 & 18.36 & 1.0 (Ref.) & - \\
\hline $\mathrm{TA}$ & 143 & 52.00 & 163 & 53.44 & $0.86(0.55-1.36)$ & 0.50 \\
\hline TT & 75 & 27.27 & 86 & 28.20 & $0.86(0.51-1.43)$ & 0.53 \\
\hline \multicolumn{7}{|l|}{$I L-10$ rs 1800872} \\
\hline GG & 158 & 57.45 & 190 & 62.30 & 1.0 (Ref.) & - \\
\hline TG & 94 & 34.18 & 99 & 32.46 & $1.14(0.79-1.65)$ & 0.46 \\
\hline $\mathrm{TT}$ & 23 & 8.36 & 16 & 5.25 & $1.73(0.84-3.63)$ & 0.11 \\
\hline \multicolumn{7}{|l|}{ IL-10 rs1800896 } \\
\hline $\mathrm{AA}$ & 78 & 28.36 & 70 & 22.95 & 1.0 (Ref.) & - \\
\hline $\mathrm{GA}$ & 127 & 46.18 & 144 & 47.21 & $0.79(0.52-1.21)$ & 0.25 \\
\hline GG & 70 & 25.45 & 91 & 29.84 & $0.61(0.37-0.94)$ & 0.10 \\
\hline
\end{tabular}

$\mathrm{OR}=$ odds ratio $; \mathrm{CI}=$ confidence interval.

\section{DISCUSSION}

This study was the first to investigate the role of cytokine genes in the risk of Candida infection among patients in a Chinese population. To our knowledge, only one study has reported on the association between cytokine genes and the susceptibility to invasive Candida infections (Johnson et al., 2012); this reported that variants of the genes IL12 $\beta$ and IL10 are correlated with systemic Candida infection persistence (Johnson et al., 2012). Our study showed that the $I L 10$ rs1800896 polymorphism was associated with a risk of invasive Candi$d a$ infections, which is consistent with the results of the previous study (Johnson et al., 2012).

Previous studies have shown that polymorphic variants of the genes for IL-12 $\beta$ and IL-10 are correlated with persistent systemic Candida infection, and that polymorphisms in other key innate immunity genes such as TLR4, TLR2, or TLR1 can play important roles in the risk of invasive Candida infections (Van der Graaf et al., 2006; Woehrle et al., 2008; Johnson et al., 2012). Johnson et al. (2012) conducted a cohort study with 338 patients with candidemia and 351 noninfected controls, and investigated single nucleotide polymorphisms (SNPs) in six cytokine genes and one cytokine receptor gene, including $I F N G, I L 10, I L 12 \beta, I L 18, I L 1 \beta$, and IL8 as well as $I L 12 R B 1$. This study found that polymorphisms in $I L 10$ and $I L 12 \beta$ could cause low production of proinflammatory cytokines, and were correlated with persistent fungemia in patients with candidemia. Fatahinia et al. (2012) investigated the efficacy of propolis on cytokine levels in systemic candidiasis in mice. They found that IL-10 counterbalanced the role of proinflammatory cytokines, including IFN-c. The IL10 rs1800896 polymorphism modified IL-10 secretion and was associated with reduced IL-10 production, and might therefore be predicted to influence the outcomes in several disease states (Stanilova et al., 2006; Zeng et al., 2009). The $I L-10$ rs1800896 polymorphism was shown to modify the response to sepsis caused by many microorganisms, and was associated with an increased rate of persistence of the infections (Hunninghake et al., 2008). Our study found that the $I L-10$ rs 1800896 polymor- 
phism was associated with the risk of invasive Candida infections, and showed that high IL-10 production was a predisposing factor for prolonged candidemia.

This study has a few limitations. First, the patients and controls were selected from two hospitals, which might not be representative of other populations. However, the controls consisted of a random sample from a pool of individuals who came to receive a health check-up, and could therefore potentially be representative of the general population. Second, because of the rarity of invasive Candida infections, the sample size of the patient group is relatively small, which could limit the statistical power to find an association between groups. Third, the risk of invasive Candida infections could be modified by many genetic factors other than cytokine genes. Therefore, further studies with more subjects are needed to confirm the association between cytokine gene polymorphisms and the risk of invasive Candida infections found in this study.

In summary, the results of this case-control study suggest that the $I L-10$ rs 1800896 polymorphism, among cytokine gene variants, might play a role in the etiology of invasive Candida infections. Further large sample studies are needed to confirm this association.

\section{Conflicts of interest}

The authors declare no conflict of interest.

\section{ACKNOWLEDGMENTS}

Research supported by grants from the National Natural Science Foundation of China (\#81000731), the Promotive Research Fund for Excellent Young and Middle-Aged Scientists of Shandong Province (\#BS2010YY045), and the Construction Program of Shandong Key Clinical Specialty.

\section{REFERENCES}

Da Matta DA, Melo AS, Guimarães T, Frade JP, et al. (2010). Multilocus sequence typing of sequential Candida albicans isolates from patients with persistent or recurrent fungemia. Med. Mycol. 48: 757-762.

Fatahinia M, Khosravi AR and Shokri H (2012). Propolis efficacy on TNF- $\alpha$, IFN- $\gamma$ and IL2 cytokines production in old mice with and without systemic candidiasis. J. Mycol. Med. 22: 237-242.

Garey KW, Rege M, Pai MP, Mingo DE, et al. (2006). Time to initiation of fluconazole therapy impacts mortality in patients with candidemia: a multiinstitutional study. Clin. Infect. Dis. 43: 25-31.

Hunninghake GM, Soto-Quirós ME, Lasky-Su J, Avila L, et al. (2008). Dust mite exposure modifies the effect of functional IL10 polymorphisms on allergy and asthma exacerbations. J. Allergy Clin. Immunol. 122: 93-98.

Johnson MD, Plantinga TS, van de Vosse E, Velez Edwards DR, et al. (2012). Cytokine gene polymorphisms and the outcome of invasive candidiasis: a prospective cohort study. Clin. Infect. Dis. 54: 502-510.

Netea MG, Brown GD, Kullberg BJ and Gow NA (2008). An integrated model of the recognition of Candida albicans by the innate immune system. Nat. Rev. Microbiol. 6: 67-78.

Romani L (2004). Immunity to fungal infections. Nat. Rev. Immunol. 4: 1-23.

Stanilova SA, Miteva LD, Karakolev ZT and Stefanov CS (2006). Interleukin-10-1082 promoter polymorphism in association with cytokine production and sepsis susceptibility. Intensive Care Med. 32: 260-266.

Van der Graaf CA, Netea MG, Morré SA, Den Heijer M, et al. (2006). Toll-like receptor 4 Asp299Gly/Thr399Ile polymorphisms are a risk factor for Candida bloodstream infection. Eur. Cytokine Netw. 17: 29-34.

Woehrle T, Du W, Goetz A, Hsu HY, et al. (2008). Pathogen specific cytokine release reveals an effect of TLR2 Arg753Gln during Candida sepsis in humans. Cytokine 41: 322-329.

Zeng L, Gu W, Chen K, Jiang D, et al. (2009). Clinical relevance of the interleukin 10 promoter polymorphisms in Chinese Han patients with major trauma: genetic association studies. Crit. Care 13: R188. 